\title{
Cancer Surveillance Project
}

National Cancer Institute

\section{Source}

National Cancer Institute. Cancer Surveillance Project. NCI Thesaurus. Code C16068.

Surveillance projects which focus on issues of cancer 